\title{
Individual music therapy for depression: randomised controlled trial ${ }^{\dagger}$
}

Jaakko Erkkilä, Marko Punkanen, Jörg Fachner, Esa Ala-Ruona, Inga Pöntiö, Mari Tervaniemi, Mauno Vanhala and Christian Gold

\section{Background}

Music therapy has previously been found to be effective in the treatment of depression but the studies have been methodologically insufficient and lacking in clarity about the clinical model employed.

\section{Aims \\ To determine the efficacy of music therapy added to standard care compared with standard care only in the treatment of depression among working-age people.}

\section{Method}

Participants $(n=79)$ with an ICD-10 diagnosis of depression were randomised to receive individual music therapy plus standard care (20 bi-weekly sessions) or standard care only, and followed up at baseline, at 3 months (after intervention) and at 6 months. Clinical measures included depression, anxiety, general functioning, quality of life and alexithymia. Trial registration: ISRCTN84185937.

\section{Results}

Participants receiving music therapy plus standard care showed greater improvement than those receiving standard care only in depression symptoms (mean difference 4.65 , $95 \% \mathrm{Cl} 0.59$ to 8.70$)$, anxiety symptoms $(1.82,95 \% \mathrm{Cl} 0.09$ to $3.55)$ and general functioning $(-4.58,95 \% \mathrm{Cl}-8.93$ to -0.24 ) at 3-month follow-up. The response rate was significantly higher for the music therapy plus standard care group than for the standard care only group (odds ratio 2.96, $95 \% \mathrm{Cl} 1.01$ to 9.02 ).

\section{Conclusions}

Individual music therapy combined with standard care is effective for depression among working-age people with depression. The results of this study along with the previous research indicate that music therapy with its specific qualities is a valuable enhancement to established treatment practices.

\section{Declaration of interest}

None.
Depression is a disabling disease ${ }^{1}$ causing problems such as a reduction in quality of life and loss of general functioning. ${ }^{2}$ In Finland, depression has become a common reason for inability to work $^{2}$ and is prevalent in $5-6.5 \%$ of the population. ${ }^{3}$ Medication together with psychiatric counselling is the most common combination in the treatment of depression. Psychotherapy has also been found to be effective, ${ }^{4}$ but verbal psychotherapy processing may be difficult or insufficient for some individuals. Therefore, therapies that allow non-verbal processing - such as music therapy - may offer a workable alternative. Music can then be seen as an alternative expressive modality and a way to get in touch with emotions and develop relationships. ${ }^{5,6}$ Free improvisation, a specific music therapy technique, has also been described as a means of 'self-projection and free association" enabling one to connect with emotional memories and images. $^{8-10}$ In recent years, some randomised controlled trials (RCTs), a Cochrane systematic review ${ }^{11}$ and a meta-analysis ${ }^{12}$ focusing on dose-response relationships in music therapy for people with serious mental disorders (including depression) have found music therapy to be an effective treatment for depression, for example, improving mood and being easily accepted by individuals. ${ }^{13}$ However, better methodological quality with more focus on clinical theories and working modes of music therapy has been demanded. Only one study ${ }^{14}$ focused on people of working age. The present study focused on a single clinical method with a clear clinical theory (improvisational, psychodynamic music therapy), a combination that is relevant in music therapy practice. ${ }^{5,9,10,15-17}$ We limited our study to working-age people because of the huge socioeconomic importance of this large population, ${ }^{2,18}$ and because of the dearth of research in this area. $^{11}$

'See editorial, pp. 92-93, this issue.

\section{Method}

\section{Participants}

The sample consisted of 79 adults with unipolar depression, ranging from 18 to 50 years of age. Inclusion criteria required that their primary diagnosis was depression, F32 or F33, according to ICD-10 classification. ${ }^{19}$ The Structured Clinical Interview for DSM-III-R (Mini-SCID) ${ }^{20}$ was used in health centres and polyclinics for diagnosing depression. In addition, a masked clinical expert (I.P.) with specific training in diagnosing depression assessed all the participants before randomisation. Anxiety was included because of the frequent comorbidity of depression and anxiety. ${ }^{21,22}$ Clients were included irrespective of medication status and were allowed to continue medication during the study. Musical skills or any given musical background were not required, although these did not exclude clients from participation. Clients were excluded if: they had a history of repeated suicidal behaviour or psychosis; they had acute and severe substance misuse; the severity of depression prevented them from participating in the measurements or engaging in verbal conversation; or they had insufficient knowledge of the Finnish language.

The study was conducted at the Music Therapy Clinic for Research and Training, University of Jyväskylä, Finland. Trial registration: ISRCTN84185937.

Recruitment began in February 2008 and continued until April 2009. Participants were recruited primarily from the Central Finland Health Care District's psychiatric health centres and the psychiatric polyclinics of Jyväskylä city. Clinicians at these centres identified potential participants among their patients and gave them information about the study. When these patients contacted us, a clinical expert (I.P.) evaluated them based on the inclusion 
and exclusion criteria. Newspaper advertisements were launched to boost recruitment. Further details of the flow of participants are provided in Fig. 1. The ethical board of the Central Finland Health Care District gave their approval for the study on 24 October 2007. In addition, all participants gave signed informed consent to the study.

\section{Randomisation}

Participants were randomised using simple randomisation with a 10:7 ratio of standard care to music therapy (details in Fig. 1). This unequal ratio was chosen to maximise feasibility and power within the given budget and time constraints. An independent person at Uni Health, Bergen, Norway, generated the randomisation list using a spreadsheet software program and kept each participant's allocation concealed from the investigators until a decision about inclusion was made. Once all baseline data had been collected and informed consent obtained, the investigators used email to receive the allocation for the respective participant. After randomisation the participants were considered part of the study regardless of whether they decided to leave the study prematurely (intention-to-treat principle).

\section{Assessment procedure}

Psychiatric assessments were conducted at baseline and at 3- and 6-month follow-up, where 3-month follow-up took place immediately after the intervention in the music therapy group, and the 6-month follow-up 3 months after the treatment had been completed.

One masked clinical expert (I.P.), with training in psychiatric nursing and long experience in psychiatry, conducted all the psychiatric assessments. The expert had in addition specific training in the treatment and assessment of depression based on collaborative care for depression (psychiatric nurses working at healthcare centres with special training in depression treatment), ${ }^{23}$ which is applied in some healthcare districts in Finland, including Jyväskylä. The assessor was masked to the participants' group assignment, and the evaluations were conducted in another physical setting outside the clinic in order to avoid accidental meetings with the members of the music therapy group. The assessor was excluded from meetings at which the masking could have been endangered. Any instances of broken masking were reported.

\section{Outcome measures}

\section{Primary outcome}

The primary outcome measure of the study was the MontgomeryÅsberg Depression Rating Scale (MADRS). ${ }^{24}$ It consists of 10 items and the total score can vary from 0 to 60. The MADRS has high joint reliability, its sensitivity to change has been shown in several studies and its predictive validity for major depressive disorder has been demonstrated. ${ }^{25}$

\section{Secondary outcomes}

The secondary outcome measures administered were the anxiety part of the Hospital Anxiety and Depression Scale (HADS-A), ${ }^{26}$ Global Assessment of Functioning (GAF), ${ }^{27,28}$ the health-related quality of life survey RAND-36 $6^{29}$ for measuring quality of life, and Toronto Alexithymia Scale (TAS-20) ${ }^{30}$ for evaluating alexithymia. The measures of general functioning and quality of life were chosen on the basis of their wide use in studies of psychological interventions for people with mental health

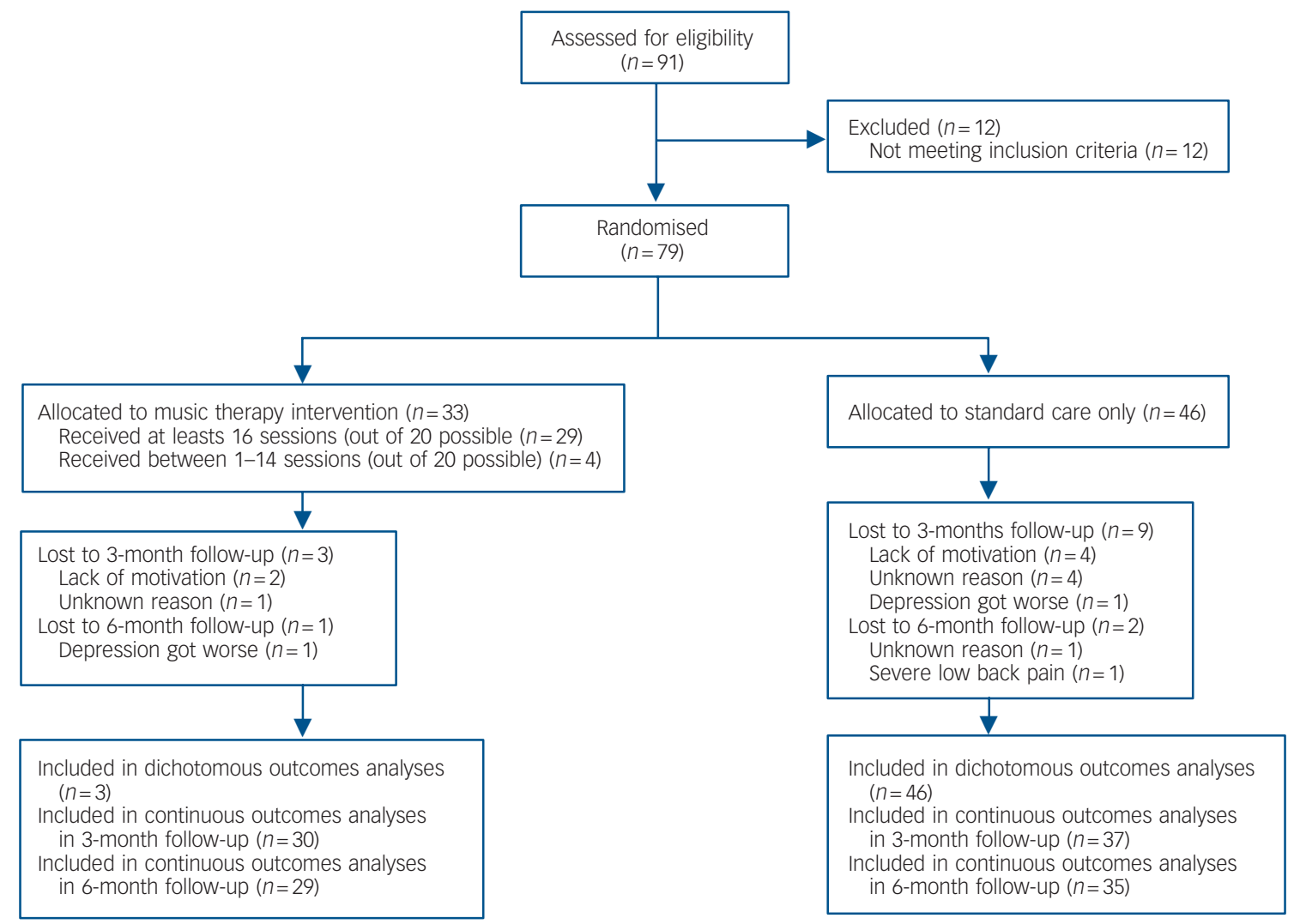

Fig. 1 Flow chart of study participants. 
problems. Alexithymia was considered in this study because it typically occurs with depression. ${ }^{31}$ Treatment response was calculated as a $50 \%$ or greater decrease in MADRS score.

Electroencephalographic biomarkers were included as additional outcomes to research the impact of music therapy on brain processing of (negative) emotions, especially in frontal areas, but these will be reported separately.

\section{Intervention}

All participants (in both the music therapy and the control group) continued to receive treatment as usual while participating in the study.

\section{Control group: treatment as usual}

In the Central Finland Health Care District, standard care included a short-term psychotherapy intervention (5-6 individual sessions) conducted by nurses specially trained in depression, medication (antidepressants) and psychiatric counselling (appointments for advice, follow-up and support when needed). The use of medication was reported.

\section{Music therapy group: individual music therapy plus treatment} as usual

Music therapy is a form of therapy that uses music experiences and client-therapist relationships for the purpose of therapeutic change. ${ }^{12}$ The music experiences used in music therapy may be varied and can range from listening to music to playing or singing songs to free improvisation; the degree of verbal reflection used in therapy sessions and the degree of structure provided by the therapist may also vary. In this study, active (i.e. clients are asked to play) music therapy was offered in an individual setting (therapist-client) according to the clinical mode ${ }^{32,33}$ developed at the Music Therapy Clinic for Research and Training, University of Jyväskylä. This model is based on an interaction between free musical improvisation and discussion, and is theoretically anchored in a psychodynamic music therapy tradition..$^{5,8,10,15-17,34}$ The basic principle of the intervention is to encourage and engage clients in expressive musical interaction. The role of the therapist is to actively facilitate and support the client's therapeutic process by using musical elements (i.e. rhythm, harmony, melody, dynamics, timbre) and interventions combined with reflective discussion. The therapeutic process is based on the mutual construction of meaning of emerging thoughts, images, emotional content and expressive qualities that often originate from the musical experience and are then conceptualised and further processed in the verbal domain. That psychodynamic theory is common in active music therapy may have arisen from conceptual commonalities between them - for example, some of the typical concepts of psychodynamics, such as emotion, metaphor, association and image, are also core elements of musical experiences. ${ }^{10,35}$

A total of 20 bi-weekly music therapy sessions were offered, each session lasting $60 \mathrm{~min}$ (conducted between May 2008 and July 2009). Musical expression in the sessions was based on a restricted selection of music instruments, including a mallet instrument (a digital mallet midi-controller), a percussion instrument (a digital midi-percussion), and an acoustic djembe drum. The therapist and the client both had identical instrumentation. All the improvisations created in the sessions were recorded either as MIDI-data or as digital audio. This made it possible to play back the improvisations for further processing and discussion. Moreover, all the sessions were video recorded for research and supervision purposes.
Ten music therapists took part in the study (three female, seven male). They all had professional training in music therapy following the highest Finnish music therapy training standards. During the study the clinicians received frequent supervision (group based, 2 monthly sessions throughout the study, presence was consistent across the clinicians) by an experienced and trained supervisor with qualifications in music therapy and psychotherapy. In case of specific questions a psychiatrist was available for consultation.

For treatment fidelity, the therapists participated in extensive training ${ }^{33}$ before the study, lasting for 15 months. The aim of the training was to achieve a common understanding about the theoretical and clinical fundamentals behind the clinical model, and to further develop the therapeutic expertise needed in the study. Lectures, real-time peer observation of the rehearsing sessions and reflective group work were used as a primary training method. During the study, video recordings of the clinical sessions were used frequently in supervision both for monitoring adherence to the method and competence in its application.

\section{Statistical analysis}

Sample size was determined using the results of a previous systematic review of dose-effect relationships in music therapy with mental disorders, from which the expected standardised mean difference of 15 sessions of music therapy for depression was predicted as $0.75 .^{12}$ We assumed that clients would attend at least 15 sessions on average, and that no more than $10 \%$ of participants would leave the study early. We arrived at $88 \%$ power for the primary outcome, with a sample size of $n=85$ (control group, 50 and music therapy group, 35; details in the study protocol). ${ }^{13}$

Data from patient notes and interviews were entered into spreadsheet files and checked independently by another person. Analyses were conducted using $R$ (version 2.7.2 for Mac). All analyses were intention-to-treat. For dichotomous outcomes, this meant that we assumed the negative outcome when the information was missing. For continuous outcomes, intentionto-treat meant that we retained data from all participants for whom the information was available. Full intention-to-treat including all randomised participants is not possible for continuous outcomes. Multiple imputations is not recommended when data are missing on dependent but not on independent variables, as it would only serve to increase standard errors. As a sensitivity analysis for the primary outcome, we assumed no change for those where the outcome was unobserved. Distributions of scores and change scores were examined graphically, and if unusual outliers were found they were excluded in a sensitivity analysis.

We calculated Fisher's exact test and odds ratios with 95\% confidence intervals for dichotomous outcomes, and Welch's $t$-test with $95 \%$ confidence intervals for changes in continuous outcomes. All tests were two-tailed. After obtaining these results, we also calculated the number needed to treat (NNT) and standardised mean difference (Cohen's $d$ ) to facilitate interpretation of clinical significance. Exploratory regression analyses were conducted to examine the possible influence of severity of depression (three levels), anxiety (yes/no), age (continuous), antidepressant medication status (yes/no), and being self-described as a musician (yes/no) or singer (yes/no). Predictors were each entered separately. The dependent variables were change in MADRS scores (linear model) and response rate (logistic model). The interaction between the treatment condition and each predictor was examined to identify whether any of these predictors had an influence on the treatment effect. Similarly, the 
therapist was examined as a predictor within the music therapy group.

\section{Results}

During the study period, 91 people were screened, of whom 79 $(87 \%)$ were eligible to participate in the study. No eligible patients refused to participate in the study and therefore 79 people $(100 \%$ of eligible patients) were randomised (Fig. 1). In total, 62 (78\%) were female; ages ranged from 18 to 50 years (mean 35.65). Of the participants, 33 were randomised to music therapy. Baseline characteristics in each arm of the trial, including medication status, are shown in Table 1. No significant difference was found on any of these characteristics.

A total of 12 participants dropped out before the 3-month follow-up and another 3 before the 6-month follow-up. The drop-out rate was higher in the control group (Fig. 1). The reasons for dropping out were lack of motivation $(n=6)$, health issues $(n=3)$ or unknown reasons $(n=6)$, i.e. the participants did not respond to the contact attempts. Among those who were followed up at 3 months, medication status was mostly unchanged.

The assessor became aware of group allocation unintentionally for two participants (the participants reported their allocation to the assessor), and for one participant intentionally (because of an adverse event).

On average, the participants assigned to the music therapy group received 18 music therapy sessions $($ s.d. $=4.7$, range $1-20$ ). A total of $29(88 \%)$ received at least 15 sessions. None of those in the control group received any music therapy. Therapy was provided by one of ten music therapists (three female) in a one-to-one setting.

During the therapy process, participants created on average 21.8 (s.d.=12.9, range 1-59) improvisations. The majority of the improvisations (mean 18.6, s.d. $=11.7$, range $1-53$ ) were therapist-client duets, but there were also solo improvisations by the clients (mean 3.2, s.d. $=3.2$, range $0-9$ ). In total, 721 improvisations (615 duets, 106 solo improvisations) were recorded over 596 sessions and are available for further analysis.

Tables 2 and 3 compare outcomes in each arm of the trial. Changes in MADRS, HADS-A, and GAF scores were significantly greater in the music therapy group than in the control arm of the trial. Modest differences in secondary outcomes as well as in 6month follow-up assessments did not reach statistical significance. However, graphical analysis suggested that differences between the groups tended to persist at 6 months for all five psychiatric measures (Fig. 2). The chances of response at 3 months were significantly greater with music therapy than with standard care (odds ratio $(\mathrm{OR})=2.96$; Table 3 ). This difference was not significant anymore at 6 months. Drop-out rates tended to favour the music therapy arm but did not reach significance. We transformed the identified effects into effect sizes (standardised mean differences) and calculated NNT to facilitate clinical interpretation (Table 4). These effect sizes are based on the intention-to-treat analysis as defined earlier. We conducted two sensitivity analyses. The first, conducted for MADRS change scores, assumed no change for those participants where the outcome was unobserved at 3 months, in order to provide a conservative estimate based on all participants initially randomised. The effect was still significant $(P<0.05)$. Second, a per-protocol analysis with one outlier excluded was conducted for all outcomes. This analysis tended to show larger effect sizes than the intention-to-treat analysis, but statistical significance levels were unchanged (not shown).

We conducted pre-planned exploratory regression analyses of change in MADRS scores and logistic regression analyses of response rates to identify potential predictors of change. Severity of depression, presence of anxiety, age, being on antidepressant medication and being self-described as a musician or a singer, were each entered separately. None of these potential predictors showed a significant interaction with the assigned group. Within the music therapy group we examined whether the therapist was a significant predictor; no such influence was identified.

Table 1 Baseline characteristics of 79 patients randomised to music therapy or standard care

\begin{tabular}{|c|c|c|c|c|c|}
\hline Characteristic & $\begin{array}{l}\text { Music therapy } \\
\text { group } \\
(n=33)\end{array}$ & $\begin{array}{l}\text { Control } \\
\text { group } \\
(n=46)\end{array}$ & $\begin{array}{l}\text { Mean difference } \\
\qquad(95 \% \mathrm{Cl})\end{array}$ & $\begin{array}{l}\text { Odds ratio } \\
(95 \% \mathrm{Cl})\end{array}$ & $P^{a}$ \\
\hline Age: years, mean (s.d.) & $35.8(9.0)$ & $35.5(10.5)$ & $0.21(-4.60$ to 4.17$)$ & & 0.92 \\
\hline Female, $n(\%)$ & $25(75.8)$ & $37(80.4)$ & & 1.31 (0.38 to 4.43$)$ & 0.78 \\
\hline Diagnosis, ${ }^{\mathrm{b}} \mathrm{n}(\%)$ & & & & & 0.77 \\
\hline F32.0 Mild depressive episode & $8(24.2)$ & $15(32.6)$ & & & \\
\hline F32.1 Moderate depressive episode & $17(51.5)$ & $21(45.7)$ & & & \\
\hline F32.2 Severe depressive episode without psychotic symptoms & $8(24.2)$ & $10(21.7)$ & & & \\
\hline Anxiety (cut-off score 8 in Hospital Anxiety and Depression Scale - Anxiety) & $28(84.8)$ & $35(76.1)$ & & & 0.40 \\
\hline \multicolumn{6}{|l|}{ Musical background (self-reported), $n$ (\%) } \\
\hline Sings & $11(33.3)$ & $12(26.1)$ & & $1.41(0.47$ to 4.21$)$ & 0.62 \\
\hline Plays an instrument & $14(42.4)$ & $13(28.3)$ & & 1.86 (0.66 to 5.33$)$ & 0.23 \\
\hline Has musical training & $7(21.2)$ & $6(13.0)$ & & $1.78(0.46$ to 7.21$)$ & 0.37 \\
\hline Self-described as a musician/singer & $9(27.3)$ & $8(17.4)$ & & $1.77(0.52$ to 6.08$)$ & 0.41 \\
\hline \multicolumn{6}{|l|}{ Current medication (self-reported), $n(\%)$} \\
\hline Any antidepressant medication & $22(66.7)$ & $35(76.1)$ & & $0.63(0.21$ to 1.91$)$ & 0.45 \\
\hline Selective serotonin reuptake inhibitors & $16(48.5)$ & $20(43.5)$ & & $1.22(0.45$ to 3.30$)$ & 0.82 \\
\hline Serotonin and noradrenaline reuptake inhibitors & $5(15.2)$ & $9(20.0)$ & & $0.72(0.17$ to 2.71$)$ & 0.77 \\
\hline \multicolumn{6}{|l|}{ Psychiatric test scores, mean (s.d.) } \\
\hline Montgomery-Åsberg Depression Rating Scale score & $24.6(6.4)$ & $23.0(7.6)$ & $1.61(-4.74$ to 1.53$)$ & & 0.31 \\
\hline Hospital Anxiety and Depression Scale - Anxiety score & $11.2(3.5)$ & $10.3(3.9)$ & $0.98(-2.66$ to 0.70$)$ & & 0.25 \\
\hline Global Assessment of Functioning score & $58.5(6.4)$ & $59.5(8.0)$ & $0.96(-2.27$ to 4.19$)$ & & 0.55 \\
\hline Toronto Alexithymia Scale score & $52.5(12.4)$ & $51.2(11.3)$ & 1.27 ( -6.73 to 4.20$)$ & & 0.64 \\
\hline Health-related quality of life survey RAND-36 score & $50.5(15.3)$ & $52.6(13.9)$ & $2.05(-4.66$ to 8.76$)$ & & 0.54 \\
\hline
\end{tabular}


Table 2 Changes in primary and secondary outcomes in the music therapy group and control group from baseline to 3 and 6 months (intention-to-treat): continuous outcomes

\begin{tabular}{|c|c|c|c|c|c|c|c|c|c|c|}
\hline \multirow[b]{2}{*}{ Outcome } & \multicolumn{5}{|c|}{ 3-month follow-up, $(n=67)^{a}$} & \multicolumn{5}{|c|}{ 6-month follow-up, $(n=64)^{\mathrm{b}}$} \\
\hline & $\begin{array}{l}\text { Mean } \\
\text { (s.d.) }\end{array}$ & $\begin{array}{l}\text { Change from } \\
\text { baseline } \\
\text { Mean }\end{array}$ & $\begin{array}{l}\text { Mean difference } \\
(95 \% \mathrm{Cl})\end{array}$ & $t$-test & $P$ & $\begin{array}{l}\text { Mean } \\
\text { (s.d.) }\end{array}$ & $\begin{array}{l}\text { Change from } \\
\text { baseline } \\
\text { Mean }\end{array}$ & $\begin{array}{l}\text { Mean difference } \\
(95 \% \mathrm{Cl})\end{array}$ & $t$-test & $P$ \\
\hline \multicolumn{11}{|l|}{$\begin{array}{l}\text { Montgomery-Åsberg } \\
\text { Depression Rating Scale }\end{array}$} \\
\hline $\begin{array}{l}\text { Control group } \\
\text { Music therapy group }\end{array}$ & $\begin{array}{l}16.43(9.33) \\
14.10(8.77)\end{array}$ & $\begin{array}{r}-6.05 \\
-10.70\end{array}$ & 4.65 (0.59 to 8.70$)$ & 2.29 & $0.03^{*}$ & $\begin{array}{c}14.74(10.65) \\
14.48(9.60)\end{array}$ & $\begin{array}{r}-6.97 \\
-10.41\end{array}$ & $3.44(-1.05$ to 7.94$)$ & 1.53 & 0.13 \\
\hline \multicolumn{11}{|c|}{$\begin{array}{l}\text { Hospital Anxiety and } \\
\text { Depression Scale - Anxiety }\end{array}$} \\
\hline $\begin{array}{l}\text { Control group } \\
\text { Music therapy group }\end{array}$ & $\begin{array}{l}8.00(4.11) \\
7.37(3.99)\end{array}$ & $\begin{array}{l}-1.95 \\
-3.77\end{array}$ & 1.82 (0.09 to 3.55$)$ & 2.11 & $0.04^{*}$ & $\begin{array}{l}7.29(4.75) \\
7.21(4.15)\end{array}$ & $\begin{array}{l}-2.46 \\
-4.10\end{array}$ & $1.65(-0.38$ to 3.67$)$ & 1.63 & 0.11 \\
\hline \multicolumn{11}{|l|}{$\begin{array}{l}\text { Global Assessment } \\
\text { of Functioning }\end{array}$} \\
\hline $\begin{array}{l}\text { Control group } \\
\text { Music therapy group }\end{array}$ & $\begin{array}{l}66.78(9.61) \\
70.00(9.37)\end{array}$ & $\begin{array}{r}6.92 \\
11.50\end{array}$ & $-4.58(-8.93$ to -0.24$)$ & -2.11 & $0.04^{*}$ & $\begin{array}{l}70.74(12.64) \\
72.90(13.89)\end{array}$ & $\begin{array}{l}10.06 \\
14.62\end{array}$ & $-4.56(-10.48$ to 1.35$)$ & -1.54 & 0.13 \\
\hline \multicolumn{11}{|l|}{$\begin{array}{l}\text { Toronto Alexithymia } \\
\text { Scale - } 20\end{array}$} \\
\hline $\begin{array}{l}\text { Control group } \\
\text { Music therapy group }\end{array}$ & $\begin{array}{l}47.43(11.99) \\
45.83(13.51)\end{array}$ & $\begin{array}{l}-4.05 \\
-6.10\end{array}$ & $2.05(-2.35$ to 6.44$)$ & 0.93 & 0.36 & $\begin{array}{l}45.77(12.80) \\
42.66(12.20)\end{array}$ & $\begin{array}{l}-5.37 \\
-8.90\end{array}$ & $3.53(-1.36$ to 8.41$)$ & 1.45 & 0.15 \\
\hline \multicolumn{11}{|l|}{$\begin{array}{l}\text { Health-related quality of } \\
\text { life survey RAND-36 }\end{array}$} \\
\hline $\begin{array}{l}\text { Control group } \\
\text { Music therapy group }\end{array}$ & $\begin{array}{l}62.59(18.20) \\
66.70(20.10)\end{array}$ & $\begin{array}{r}9.86 \\
14.37\end{array}$ & -4.50 (-11.40 to 2.40$)$ & -1.30 & 0.20 & $\begin{array}{l}64.60(18.74) \\
67.93(18.51)\end{array}$ & $\begin{array}{l}10.80 \\
14.93\end{array}$ & $-4.13(-11.83$ to 3.57$)$ & -1.07 & 0.29 \\
\hline $\begin{array}{l}\text { a. Control group } n=37 \text {; musi } \\
\text { b. Control group } n=35 \text {; musi } \\
\star P<0.05 \text {. }\end{array}$ & $\begin{array}{l}\text { ic therapy grou } \\
\text { ic therapy grou }\end{array}$ & & & & & & & & & \\
\hline
\end{tabular}

Table 3 Changes in primary and secondary outcomes in the music therapy group and control group from baseline to 3 and 6 months (intention-to-treat): dichotomous outcomes ${ }^{a}$

\begin{tabular}{|c|c|c|c|c|c|c|}
\hline \multirow[b]{2}{*}{ Outcome } & \multicolumn{3}{|c|}{ 3-month follow-up } & \multicolumn{3}{|c|}{ 6-month follow-up } \\
\hline & $n / N(\%)$ & Odds ratio $(95 \% \mathrm{Cl})$ & $P$ & $n / N(\%)$ & Odds ratio $(95 \% \mathrm{Cl})$ & $P$ \\
\hline \multicolumn{7}{|l|}{ Leaving the study early } \\
\hline Control group & 9/46 (20) & $0.42(0.07-1.86)$ & 0.34 & $11 / 46(24)$ & $0.44(0.09-1.70)$ & 0.25 \\
\hline Music therapy group & $3 / 33(9)$ & & & 4/33 (12) & & \\
\hline \multicolumn{7}{|l|}{ Response $^{\mathrm{b}}$} \\
\hline Control group & $10 / 46(22)$ & $2.96(1.01-9.02)$ & $0.03^{*}$ & $16 / 46(35)$ & $1.38(0.49-3.82)$ & 0.64 \\
\hline Music therapy group & 15/33 (45) & & & 14/33 (42) & & \\
\hline
\end{tabular}

\begin{tabular}{|l|l|}
\hline Table 4 Clinical relevance of the effects of individual music therapy: effect sizes and number needed to treat ${ }^{\mathrm{a}}$ \\
\hline Montgomery-Åsperg Depression Rating Scale & Effect size, $d \quad 0.65$ \\
\hline Hospital Anxiety and Depression Scale - Anxiety & 0.49 \\
\hline Global Assessment of Functioning & 0.62 \\
\hline Response & Nifference, \% needed to treat \\
\hline $\begin{array}{l}\text { a. All analyses intention-to-treat. Effect sizes were calculated as the difference in change at 3 months divided by the pooled standard deviation at baseline (Table 1), with signs } \\
\text { reversed where applicable so that a positive effect size indicates a difference in favour of music therapy. Risk difference and number needed to treat are based on the numbers } \\
\text { with no response at } 3 \text { months (Table 3). }\end{array}$ \\
\hline
\end{tabular}

Adverse events were noted for a few participants. Two participants (one in each arm of the trial) experienced a significant worsening of their depression, leading them to quit the study early; one participant in the control group developed severe low back pain (Fig. 1).

\section{Discussion}

This trial has shown that music therapy added to standard care helps people with mild, moderate or severe depressive episodes to improve their levels of depression as well as anxiety and functioning. The response rate was significantly greater in music therapy, compared with those who only received standard care. Effects were clinically relevant, with effect sizes in the mediumto-large range (ranging from 0.65 for depression to 0.49 for anxiety). The NNT was four, indicating that one person will change from no response to response for every four people to whom music therapy is offered. These estimates are based on an intention-to-treat analysis, which means that they are likely to underestimate the effects of treatment for those who received it. Another interesting finding is the high attendance rate. Average attendance of 18 sessions out of 20 shows a high level of engagement and sustained involvement. 
(a)

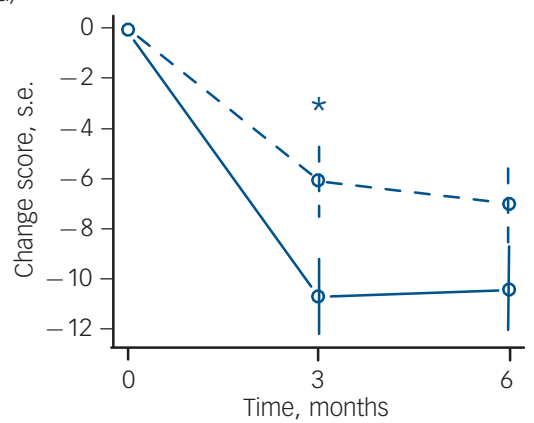

(d)

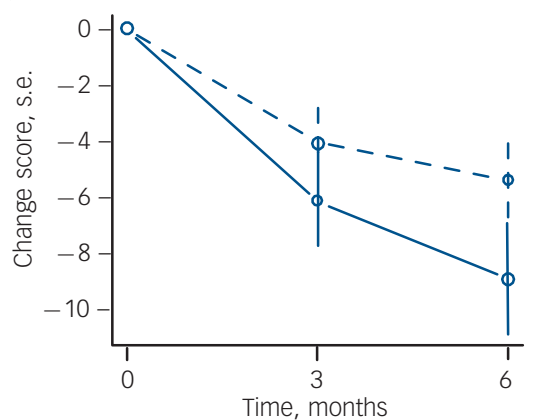

(b)

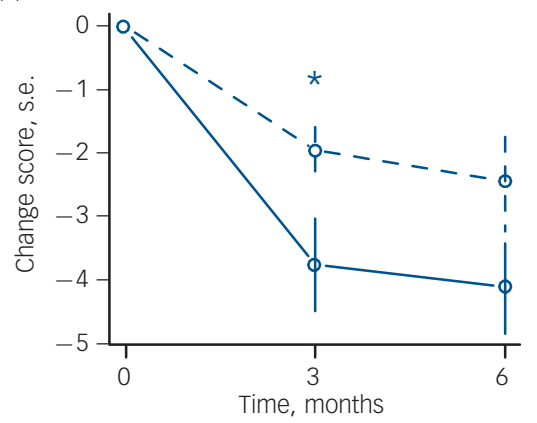

(e)

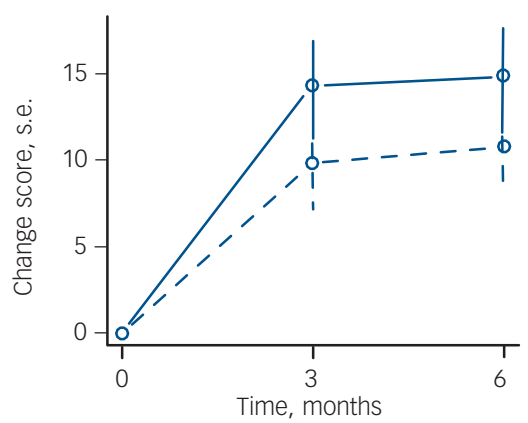

(c)

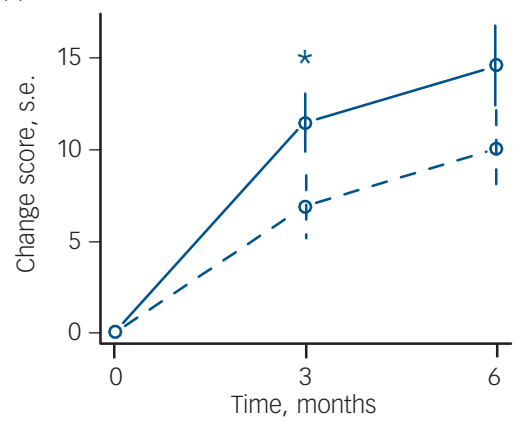

Music therapy

Fig. 2 Changes in psychiatric tests. (a) Montgomery-Åsberg Depression Rating Scale; (b) Hospital Anxiety and Depression Scale - Anxiety; (c) Global Assessment of Functioning; (d) Toronto Alexithymia Scale - 20; (e) Health-related quality of life scale RAND-36.

${ }^{*} P<0.05$.

\section{Matching research and clinical methods}

The main limitations of previous RCTs on music therapy for depression were that the clinical method was not clearly defined or was diverse; also, a typical working-age population were rarely included, and the methodological quality was generally poor. ${ }^{11}$ In particular, earlier music therapy research has suffered from an imbalance between research methods and clinical methods. ${ }^{10,12,36}$ Flexible and process-oriented clinical methods that are prevalent in clinical practice have most commonly been investigated using qualitative process research. Conversely, quantitative research methods have been applied more commonly to highly structured clinical methods that music therapists do not commonly apply. Similar tendencies exist in psychotherapy research in general, where the effects of more structured approaches (e.g. cognitive-behavioural models) have also been more rigorously investigated than more process-oriented ones (e.g. psychodynamic psychotherapy). ${ }^{37}$ Yet the imbalance might have been even more extreme in music therapy, with the result that RCTs of music therapy methods that are commonly applied are rare and evidence for them is sparse. ${ }^{6,11,12,38}$ As the first RCT on improvisational music therapy for depression, the present study fills an important gap in knowledge and may also contribute to innovating the research culture in music therapy towards greater clinical applicability and relevance of outcome research.

\section{Translation into clinical practice}

The present study supports and further clarifies earlier clinical findings that suggested that music therapy has specific qualities that enable meaningful non-verbal expression and interaction even in those situations where the client cannot verbally describe their inner experiences. ${ }^{5,9}$ Clinical improvisation is said to be able to operate on a protosymbolic level $\mathrm{l}^{5}$ by triggering unconscious processes beyond the pathology and, in a way, to prepare the client for fully symbolic expression and eventually for verbalising. In this way musical interaction in music therapy can be seen as a preverbal $^{39}$ or early ${ }^{9}$ mode of communication, which may serve to extend and complement verbal expression and communication. For many clients in the music therapy group, experiences during the non-verbal act of musical expression led them to insights of certain aspects of their psychopathology as the experiences were further processed in the verbal domain. For example, it can happen in clinical improvisation that emotional memories about the domestic atmosphere in early childhood are triggered by musical interaction with the therapist. In general, the additional value of improvisational music therapy with these clients seemed to be that it enabled working with and experiencing emotions associated with depression on a symbolic, non-verbal level. Musical, improvisational interplay between the client and the therapist also offers an open stage for transferences and creative imagery.

Classical psychoanalytic thinking explains depression through traumatic events in one's biography, often associated with dramatic losses and lack or deficit of love. ${ }^{40,41}$ Our study supports this viewpoint. Participants in music therapy often found reasons for their condition in past events and relationships based on their own initiative, even though clinicians were instructed not to manipulate clients in this direction.

That music therapy includes active doing - i.e. playing music instruments - was important to many clients. Inner pressure and feelings were often expressed by drumming or by the tones produced with a mallet instrument. Clients sometimes described their playing experience as cathartic, and this may have led to corrective emotional experiences in further processing. A rather unique property of music therapy is the fact that it includes the opportunity to be active and this seems to be a meaningful dimension for dealing with issues associated with depression.

We assume that the bi-weekly scheduling of sessions increased the intensity of the therapy and thereby contributed to positive outcomes. For research purposes, the clinical setting (instruments 
and clinical techniques available) was more restricted than in everyday music therapy practice. In our experience, however, this did not have a negative influence on the results.

Although not significant, the trend towards a reduction in alexithymia that was seen both at 3 and 6 months is interesting. Music therapy's putative mechanisms of change, involving emotion recognition and expression, are directly related to the concept of alexithymia. Further research is needed to find out whether music therapy has an effect in reducing alexithymia in people with depression.

\section{Limitations}

The present trial was larger and more rigorous than previous studies, but might still be regarded as an exploratory trial in a statistical sense. The sample size was sufficient to detect an effect in the primary outcome at the end of therapy, but not at 6 months, even though graphical analyses suggested that the effect tended to persist. Second, the present trial used a simple two-arm design of music therapy with standard care versus standard care alone. It was designed to address the most policy-relevant question of interest, that is whether music therapy is superior to the usual treatment offered to that population, not to address the mechanism of change or the specific ingredients of music therapy. However, we examined whether the effect of music therapy varied significantly across therapists - a common criticism from common factors research in psychotherapy - and found no such indication. This lack of significant variation of effects between therapists might be an indication that the effect was based on the music therapy method utilised. Finally, an analysis of cost-effectiveness (or other health economic analysis) was not included in the present study, but would be useful and relevant for future studies. The achievement of the present study is to have demonstrated music therapy's effectiveness over and above an already quite highly developed standard of care for people with depression.

\footnotetext{
Jaakko Erkkilä, PhD, Marko Punkanen, Lic Phil, Jörg Fachner, Dr rer medic, Jaakko Erkkilä, PhD, Marko Punkanen, Lic Phil, Jörg Fachner, Dr rer medic,
Esa Ala-Ruona, PhD, Finnish Centre of Excellence in Music Research, University of Esa Ala-Ruona, PhD, Finnish Centre of Excellence in Music Research, University of
Jyväskylä, Finland; Inga Pöntiö, Master of Nursing Science, Central Finland Health Care District, Jyväskylä, Finland; Mari Tervaniemi, PhD, Finnish Centre of Excellence in Music Research, University of Jyväskylä, Finland, Cognitive Brain Research Unit, University of Helsinki, Finland, Department of Psychology, University of Jyväskylä, Finland; Mauno Vanhala, DMedSC, Unit of Family Practice, Central Finland Centra Hospital, Jyväskylä and Kuopio University Hospital and University of Eastern Finland Kuopio, Finland; Christian Gold, PhD, GAMUT, Uni Health, Bergen, Norway

Correspondence: Christian Gold, GAMUT, Uni Health, Lars Hilles gt. 3, 5015 Bergen, Norway. Email: Christian.gold@uni.no

First received 4 Aug 2010, final revision 24 Oct 2010, accepted 17 Nov 2010
}

\section{Funding}

The NEST (New and Emerging Science and Technology) programme of the European Commission (project BrainTuning FP6-2004-NEST-PATH-028570), and the programme for Centres of Excellence (COEs) in research, Academy of Finland.

\section{Acknowledgements}

The authors would like to thank Tony Wigram for advice on the design of the study, Timo Männikkö for clinical supervision and collaboration, Petri Toiviainen for advice on the project management, Thomas Wosch for advice on alexithymia, Markku Pöyhönen for practical arrangements of the study, and Lasse Pulli for clinical supervision of the therapists. Geoff Luck and Fiona Kirkwood Brown have helped with language corrections.

\section{References}

1 Sobocki P, Jönsson B, Angst J, Rehnberg C. Cost of depression in Europe. J Ment Health Policy Econ 2006; 9: 87-98.
2 Lönnqvist J. Stressi ja Depressio. [Stress and Depression.] Kustannus Oy Duodecim, 2009 (http://www.terveyskirjasto.fi/terveyskirjasto/ tk.koti?p_artikkeli=seh00020).

3 Tuulari J, Aromaa E, Herberts K, Wahlbeck K. Pohjalainen masennus ja hakeutuminen hoitoon [Ostrobothnian depression and seeking for treatment]. Suomen Lääkärilehti 2007; 62: 790-91.

4 Isometsä E, Jousilahti $P$, Lindfors $O$, Luutonen S, Marttunen M, Pirkola S, et al. Depressio - Käypä hoito. [Depression - Current Care]. Kustannus Oy Duodecim, 2010 (http://www.kaypahoito.fi/web/kh/suositukset/ naytaartikkeli/ . . . /hoi50023).

5 De Backer J. Music and psychosis: a research report detailing the transition from sensorial play to musical form by psychotic patients. Nord J Music Ther 2008; 17: 89-104.

6 Gold C, Heldal TO, Dahle T, Wigram T. Music therapy for schizophrenia or schizophrenia-like illnesses. Cochrane Database Syst Rev 2005; 2: CD004025.

7 Hadley S. Psychodynamic music therapy: an overview. In Pschodynamic Music Therapy: Case Studies (ed S. Hadley): 1-22. Barcelona Publishers, 2003

8 Erkkilä J. Musical improvisation and drawnings as tools in the music therapy of children. Nord J Music Ther 1997; 6: 112-20.

9 Erkkilä J. From signs to symbols, from symbols to words - about the relationship between music and language, music therapy and psychotherapy. Voices. 2004; 4 (https://normt.uib.no/index.php/voices/article/viewArticle/ 176).

10 Erkkilä J, Ala-Ruona E, Punkanen M, Fachner J. Perspectives on creativity in improvisational, psychodynamic music therapy. In Musical Imaginations: Multidisciplinary Perspectives on Creativity, Performance and Perception (eds D. Hargreaves, D. Miell, R. MacDonald). Oxford University Press (in press).

11 Maratos AS, Gold C, Wang X, Crawford MJ. Music therapy for depression. Cochrane Database Syst Rev 2008; 1: CD004517

12 Gold C, Solli H, Krüger V, Lie S. Dose-response relationship in music therapy for people with serious mental disorders: systematic review and meta-analysis. Clin Psychol Rev 2009; 29: 193-207.

13 Erkkilä J, Gold C, Fachner J, Ala-Ruona E, Punkanen M, Vanhala M. The effect of improvisational music therapy on the treatment of depression: protocol for a randomised controlled trial BMC Psychiatry 2008; 8: 50.

14 Radulovic R. The use of Music Therapy in Treatment of Depressive Disorders. Unpublished Master Thesis. Faculty for Medicine, Insitute of Psychiatry Clinical Centre of Serbia, University of Belgrade, 1996.

15 Eschen JT. Analytical Music Therapy. Jessica Kingsley Publishers, 2002

16 Priestley M. Music Therapy in Action. Constable, 1975.

17 Priestley M. Essays on Analytical Music Therapy. Barcelona Publishers, 1994.

18 Honkonen $\mathrm{T}$, Aro $\mathrm{T}$, Isometsä $\mathrm{E}$, Virtanen $\mathrm{M}$, Katila $\mathrm{H}$. Quality of treatment and disability compensation in depression: compariosn of 2 nationally representative samples with a 10-year Interval in Finland. J Clin Psychiatry 2007; 68: 1886-93.

19 World Health Organization. The ICD-10 Classification of Mental and Behavioural Disorders: Clinical Descriptions and Diagnostic Guidelines. WHO, 1992.

20 Spitzer RL, Williams JB, Gibbon M, First MB. Structured Clinical Interview for DSM-III-R: The Mini-SCID. American Psychiatric Press, 1992.

21 Aina $Y$, Susman JL. Understanding comorbidity with depression and anxiety disorders. J Am Osteopath Assoc 2006; 106: 509-14.

22 Cassidy EL, Lauderdale S, Sheikh Jl. Mixed anxiety and depression in older adults: clinical charasteristics and management. J Geriatr Psychiatry Neurol 2005; 18: 83-8.

23 Bower P, Gilbody S, Richards D, Fletcher J, Sutton A. Collaborative care for depression in primary care. Making sense of a complex intervention: systematic review and meta-regression. Br J Psychiatry 2006; 189: 484-93.

24 Montgomery SA, Åsberg M. A new depression scale designed to be sensitive to change. Br J Psychiatry 1979; 134: 382-9.

25 Rush AJ, First MB, Blacker D. Handbook of Psychiatric Measures (2nd edn). American Psychiatric Publishing, 2008.

26 Zigmond AS, Snaith RP. The hospital anxiety and depression scale. Acta Psychiatr Scand 1983; 67: 361-70.

27 Hall RCW. Global assessment of functioning - a modified scale. Psychosomatics 1995; 36: 267-75.

28 Jones SH, Thornicroft G, Coffey M, Dunn G. A brief mental health outcome scale - reliability and validity of the Global Assessment of Functioning (GAF). Br J Psychiatry 1995; 166: 654-9.

29 Aalto A-M, Aro AR, Teperi J. RAND-36 terveyteen liittyvän elämänlaadun mittarina. Mittarin luotettavuus ja suomalaiset väestöarvot. [RAND-36 as a measure of health-related quality of life. Reliability, construct validity and 
reference values in the Finnish general population.] Stakes, 1999 (http:// www.stakes.fi/verkkojulkaisut/muut/Tu101.pdf).

30 Taylor GJ, Ryan D, Bagby RM. Toward the development of a new self-report alexithymia scale. Psychother Psychosom 1985; 44: 191-9.

31 Honkalampi K, Hintikka J, Laukkanen E, Lehtonen J, Viinamäki H. Alexithymia and depression - a prospective study of patients with major depressive disorder. Psychosomatics 2001; 42: 229-34.

32 Erkkilä J. Näkökulmia psykodynaamiseen musiikkipsykoterapiaan. [Perspectives on psychodynamic music therapy.] Musiikkiterapia 2005; 20: $33-42$.

33 Erkkilä J. Improvisaatiopainotteisen musiikkiterapian kokemuspohjaisia sisältöjä [Experience-based contents of improvisational music therapy]. Musiikkiterapia 2007; 22: 76-88.

34 Bruscia KE. The Dynamics of Music Psychotherapy. Barcelona Publishers, 1998.
35 Wigram T, Nygaard Pedersen I, Bonde LO. A Comprehensive Guide to Music Therapy. Jessica Kingsley Publishers, 2002.

36 Rolvsjord R, Gold C, Stige B. Research rigour and therapeutic flexibility: Rationale for a therapy manual developed for a randomised controlled trial. Nord J Music Ther 2005; 14: 15-32.

37 Leichsenring F, Rabung S. Effectiveness of long-term psychodynamic psychotherapy. JAMA 2008; 300: 1551-65.

38 Gold C, Wigram T, Elefant C. Music therapy for autistic spectrum disorder. Cochrane Database Syst Rev 2006; 2: CD004381.

39 Rolvsjord R. Music as a poetic language. Voices 2004; 4 (https:// normt.uib.no/index.php/voices/article/viewArticle/141/117).

40 Freud S. Trauer und melancholie [Mourning and melancholia]. Int $Z$ Psychoanal 1917; 4: 288-301.

41 Rado S. Psychodynamics of depression form the etiologic point of view. Psychosom Med 1951; XIII: 51-5.

\section{Fiona Shaw}

When I began writing this book, I did so in the effort to shore myself up against the whirling chaos of my mind. I was in fear of disintegration, though I couldn't, and still can't describe what I mean by that. I had no idea that my terror would give birth to a book. What has been important has been the act of turning blankness and confusion into narrative coherence, however provisional. And though I started by doing that with my experience after Jesse's birth, I quickly found myself doing the same thing with my earlier life. Though it's not effaced from my memory in quite the same way as the more recent past, I had no sense of coherence for any of it. I didn't know, before I began, how to go about making it out.

Two weeks in, the first shock of ECT ringing in my skull, continuity went. What I have left are mostly incidental snapshots of memory, recollections in monochrome, without atmosphere or expression. There is no affect, as a psychiatrist might say. They have none of the contrast of black and white, none of the warmth of colour. Were I to make a montage with them, all I'd have would be the static posture of someone who had lost her animation and was living a life by rote. From the start of my breaking down, Hugh was shocked by how much I seemed entirely myself. It seemed more terrible to him than if I had been unlike. But the narrowed, self-hating, minimal self, brittle as a Giacometti sculpture, that he visited every day is lost to my memory once ECT had begun. I no longer remember the shape of my despair. There is only a figure in grey, without thoughts or actions, without a voice even. No rage any more, waxing or waning.

Fiona Shaw described her experience of puerperal psychosis in Out of Me: The Story of a Postnatal Breakdown. It is an eloquent examination and exploration of the origins, nature and consequences of severe mental illness in the postpartum period. This excerpt is from Out of Me (pp. 72 \& 204), Penguin Books, 1997. 